\title{
The Learning Trajectory Construction of Elementary School Students in Solving Integer Word Problems
}

\author{
Andi Saparuddin Nur * \\ Doctoral Program of Mathematics Education, Universitas Negeri Semarang, \\ Indonesia ORCID: 0000-0003-0278-2280
}

\author{
Kartono Kartono \\ Department of Mathematics Education, Universitas Negeri Semarang, Indonesia \\ ORCID: 0000-0002-0675-7595
}

\author{
Zaenuri Zaenuri \\ Department of Mathematics Education, Universitas Negeri Semarang, Indonesia \\ ORCID: 0000-0002-6243-3405
}

\section{Rochmad Rochmad}

Department of Mathematics Education, Universitas Negeri Semarang, Indonesia ORCID: 0000-0003-1146-4508

\begin{tabular}{ll}
\hline \hline Article history & The integer is a basic concept in studying arithmetic and algebra. \\
Received: & However, students still frequently experience misconceptions, especially \\
07.01 .2021 & in negative integer, count operations. Traditional games are activities that \\
Received in revised form: & are often carried out by students in coastal areas so that they are relevant \\
& to be used as a tool to construct learning trajectories in solving integer \\
22.06 .2021 & word problems. The aim of this study is to produce a learning trajectory \\
Accepted: & that can be used to solve integer word problems using traditional games. \\
05.07 .2021 & This study used a design-based research. Participants in this study were \\
& five grade sixth elementary school students. There are 6 sub-topics \\
Key words: & studied, i.e., the concept of negative integers, sequence integers, addition \\
\hline Learning trajectory, & and subtraction operations, division and multiplication operations, mixed \\
Word problems, & count operations, and solving problems related to integers. The results of \\
Traditional games, & this study obtained student learning trajectories for each sub-topic \\
Integers. & including the free play, collecting data from the game results, making \\
& mathematical relationships, building concepts, and applying them to \\
& various problems. Students are able to do problem-solving based on the \\
& sequence of tasks but require intervention so they can apply it to other \\
& situations without engaging in activities. Further research is required for \\
more in-depth exploration on thinking process, instruction types, and & behaviours that students might display independently without using \\
& traditional games in solving integer word problems. \\
\hline \hline
\end{tabular}

\footnotetext{
* Correspondency: andisaparuddin@ students.unnes.ac.id
} 


\section{Introduction}

The process of learning mathematics cannot be separated from the characteristics of the interaction students have with their social environment. Students follow the natural mathematics learning progression, including mathematical ideas and skills in their own way (Clements \& Sarama, 2009). Mathematical knowledge can be constructed through activities that come from students' daily lives and used as a starting point for learning. The development trajectories with the sequence of activities that build up the student learning environment is referred to as Learning Trajectory (LT). LT refers to a representation of learning that describes how students engage in assignments and develop their knowledge through various activities (Weber, Walkington, \& Mcgalliard, 2015). LT discusses the interaction of innate competencies, internal resources, and experiences in students' thoughts and actions (Barrett et al., 2012). The teacher's important role is to shape and organize student experiences into a tool that can be used in the learning process (Ellis et al., 2016).

The learning and teaching process has a connected side that has not been studied specifically (Sztajn et al., 2012). A concept has meaning for students if the construction process involves learning experiences and activities that are relevant to their daily lives. LT has the potential to support better student understanding, enable more effective teaching strategies while achieving curriculum goals with better design standards (Ellis et al., 2016). Teachers' understanding of students' learning trajectories is very useful in mapping proper pedagogical practices, including treatment, stimulation, and scaffolding. A person can grow to the next level, but it is also possible to go down to the previous level as a form of adapting cognitive schemes when overcoming difficulties (Barrett et al., 2012).

Each learning step from LT departs from the idea of a Hypothetical Learning Trajectory (HLT), which is an assumption of expected student activity (Weber \& Lockwood, 2014). HLT consists of hypothesized learning objectives, interventions, and learning processes (Simon, 2018). Planned interventions in teaching are a sequence of tasks that can construct a concept. Simon \& Tzur (Weber, Walkington, \& Mcgalliard, 2015) use four principles in defining HLT, i.e., 1) HLT is based on current student understanding, 2) HLT is a way of planning learning for certain mathematical concepts, 3) the provided assignment facilitates concept learning so that it becomes an important part of the learning process, and 4) HLT is uncertain in nature so involvement is needed to modify every aspect of HLT. Modifying the HLT is the result of an analysis performed when the sequence of tasks does not reveal concept building (Simon, 2018). HLT that has gone through the teaching process is the result of the construction of student learning trajectories.

LT has three parts, i.e., a mathematical goal, a developmental trajectories in which students develop towards that goal, and a series of teaching activities or assignments tailored to each level of thinking in a pathway that helps students develop higher levels of thinking (Clements \& Sarama, 2009). The stages of the LT approach are task-based activities which are divided into four stages. The first stage is the informal one, which uses mathematical thinking from the context of experience, the second stage is the model of the process in describing mathematical concepts, the third stage constitutes a model, namely a model for the descriptive transition from informal mathematics to abstraction, and the fourth stage is the formal model, i.e., mathematical abstraction used to solve problems based on a context of experiences (Gravemeijer, 2004).

An important part of learning that involves the abstraction process is the participatory and anticipatory stages (Simon et al., 2016). The participatory stage is an activity where students 
are involved in activities that support task completion. The assignment is designed in order so that the abstraction process can be formed gradually, and students can anticipate the assignment completion without having to be involved in activities. The anticipatory stage is formation assessment of an abstraction that shows students are able to think about completing a task without doing activities. However, there has not been an adequate task design to facilitate the transition from the participatory to the anticipatory stage. Therefore, instructional interventions are needed that link the objectives of the anticipatory stage with the abstraction underlying the participatory stage (Simon et al., 2016).

Learning the concept of numbers is a topic that often creates misconceptions (Sun, 2018). The concept of numbers is indispensable in performing basic arithmetic skills, but student errors are very common in that area. Students often have not been able to develop an understanding of the numbers concept but have been required to study the next material. As a result, students lose the opportunity to use arithmetic skills better. Arithmetic learning is very important for students because it is applied in daily activities and becomes the core in basic mathematics (Zhang et al., 2019). Especially in integer arithmetic operations, students experience difficulty in representing negative integers and difficulty using integer operating procedures in problem solving.

Problem solving is related to word problems, and related to interpretation of textual situations obtained from mathematical operations to numerical data in various contexts (Verschaffel et al., 2020). Word problems are used to offer practice in situations close to the context of everyday life to become a stimulus for students to solve problems and make mathematical modelling more formal. Explicit word problem solving algorithms are best taught to elementary school students (Csíkos \& Szitányi, 2020). A problem-solving approach can begin by developing students' thinking skills that depart from their learning styles. Learning activities by involving strategy and students' experiences in problem solving are very important to provide meaningful learning opportunities (Isoda, 2010; Özkubat et al., 2020).

Learning trajectory has a role in tracing the thinking process of students solving word problems related to integers (Harel \& Koichu, 2010). However, studies on LT involving traditional game activities have not received much attention. LT studies focus more on mental processes and stages that support students in achieving reflective abstraction (Simon et al., 2016), while exploration of word problem solving has not been done much. Constructing students' LT can be done using traditional game activities. Using a traditional game context promises a better understanding of constructing student learning trajectories in solving word problems on the integers concept. Understanding the constructs used by students will have an impact on improving the didactic process and ultimately fostering the ability to internalize concepts in various applications. Based on this description, the research questions of this study, are (1) How can traditional games be used to construct students' learning trajectories in solving integer word problems? (2) What is the sequence of students' learning trajectories solving integer word problems using traditional games? (3) What are the obstacles encountered by students in solving integer word problems using traditional games?

\section{Methods}

\section{Research Design}

This study used a design-based research that aims to construct students' learning trajectories in solving integer word problems. This research includes two stages, i.e., teaching 
experiments, and retrospective analysis (Gravemeijer, 2004; Prediger et al., 2015). The teaching experiment is an activity to prepare the initial HLT and design a tasks sequence that supports student problem solving construction from the participatory stage to the anticipatory stage (Simon, 2018). The learning process facilitates students' learning that is necessary to build concept knowledge that supports reflective abstraction abilities. Retrospective analysis is an activity that determines the future learning stage. If the planned HLT does not support the concept building, a revised HLT is carried out for use in further learning (Weber, Walkington, \& McGalliard, 2015).

\section{Participant}

The subjects of this study were five grade sixth students of the elementary school in Jeneponto Regency, South Sulawesi Province, Indonesia, with 2 male, and 3 female students. Participants were selected based on their level of mathematical knowledge, gender, parent's occupation, and age. Participants' mathematical knowledge is identified through short questions related to integer operations and confirmed through interviews with class teachers. Gender is taken into consideration for assessing the learning trajectory in solving problems because various studies have shown a relationship between the two (Carter et al., 2020; Fonger et al., 2020). The parents' career background also indicates a different way of thinking in solving problems because it is related to social and economic status (Fonger et al., 2020). The age of the participants was chosen in the range of 11-13 years as an appropriate time to recognize the concept of integers in various contexts (Dröse \& Prediger, 2020; Stephan \& Akyuz, 2012; Sun, 2018; Zhang et al., 2019). Subjects come from low-income parents with a homogeneous coastal cultural background who work as fishermen, drivers, salt farmers, rice farmers and retailer. The selected participants in this study (pseudonym) can be seen in Table 1.

Table 1. Research participants based on criteria

\begin{tabular}{lllll}
\hline Name & Mathematics Level & Gender & Parents' occupation & Age (Year) \\
\hline Andın & High & Female & Rice farmers & 12 \\
Anto & High & Male & Drivers & 12 \\
Galang & Medium & Male & Salt farmers & 12 \\
Lila & Medium & Female & Fishermen & 13 \\
Rani & Less & Female & Retailer & 11 \\
\hline
\end{tabular}

All students did not have learning experiences related to negative integers, but they already knew whole numbers. The teaching implementation lasts for two months at students' homes and is limited in schools due to the COVID-19 pandemic.

\section{Procedure}

The research implementation focused on constructing student learning trajectories in solving integer word problems. The first stage was determining the students' initial understanding as a prerequisite ability that must be possessed. Understanding the prerequisites shows the initial HLT contained in a concept before the further ability can be carried out. Furthermore, the researcher designed a task that supported the understanding on the learning objectives. Design assignments should provide opportunities for students to construct their knowledge without following formal rules. The construction of student learning trajectories can be understood through gradual mental actions from playing activities, collecting data, making mathematical relationships, and representing them in formal form. The validity test for the obtained data was carried out by briefly discussing the results of students' response through retrospective analysis with the teacher. The retrospective analysis consists of three 
levels, i.e., the stage of selecting data related to student participatory processes, continuing data analysis at the transition stage, and using the sequence of tasks that appear as the basis for making the revised HLT. There are six sub-concepts proposed in this study, i.e., negative integers, sequence integers, addition and subtraction, multiplication and division, mixed count, and word problems related to integers. The tools used for learning are traditional game tools, i.e., marbles, rubber bands, and involving various task-based activities.

\section{Data Collection and Analysis}

Data collection was carried out using student activity sheets containing the tasks sequence to achieve learning objectives. The results of the students' answers and activities were further analyzed through a brief discussion regarding the data. The information obtained on the students' worksheets was synchronized with the discussion results for further retrospective analysis. The students' learning trajectories were revealed by describing the abilities in each sequence of tasks. Ideally, students will go through each tasks sequence gradually as participatory stage implication towards the anticipatory stage in learning activities. However, if there are differences in the hypothesized learning trajectory with students' learning activities, then HLT revision is obtained and becomes the basis for findings further learning improvement. Information related to data is kept confidential by encoding the results of students' answers and responses. The activity stages were observed and documentation during the learning process. Teachers participate as observers and collaborate with researchers in providing recommendations related to retrospective analysis. 
Table 2. Task descriptions and achievement of learning objectives along with HLT conjectures

\begin{tabular}{|c|c|c|c|c|c|c|}
\hline \multirow[t]{2}{*}{ Sub Concept } & \multicolumn{4}{|l|}{ Task Description } & \multirow[t]{2}{*}{ Learning Objectives } & \multirow[t]{2}{*}{ HLT Conjectures } \\
\hline & Informal & Model of & Model for & Formal & & \\
\hline $\begin{array}{l}\text { Negative } \\
\text { integers }\end{array}$ & $\begin{array}{l}\text { Collect marbles } \\
\text { freely and list them. }\end{array}$ & $\begin{array}{l}\text { Play marbles and } \\
\text { calculate the difference } \\
\text { in the results of the } \\
\text { game. }\end{array}$ & $\begin{array}{l}\text { List the game results } \\
\text { in a table and find } \\
\text { negative number } \\
\text { concepts. }\end{array}$ & $\begin{array}{ll}\text { Generalize a large } \\
\text { negative } \\
\text { number } \\
\text { number }\end{array}$ & $\begin{array}{l}\text { Students can understand } \\
\text { the use of negative integer } \\
\text { symbols and their position. }\end{array}$ & $\begin{array}{l}\text { Students can interpret the } \\
\text { concept of negative } \\
\text { integers. }\end{array}$ \\
\hline $\begin{array}{l}\text { Sequence } \\
\text { integers }\end{array}$ & $\begin{array}{l}\text { Collect the marbles } \\
\text { and rubber bands } \\
\text { freely. }\end{array}$ & $\begin{array}{l}\text { Play marbles and } \\
\text { rubber bands and list } \\
\text { the results of the games } \\
\text { in each session. }\end{array}$ & $\begin{array}{l}\text { Count the number of } \\
\text { marbles and rubber } \\
\text { bands. }\end{array}$ & $\begin{array}{l}\text { Sequence the } \\
\text { number of marbles } \\
\text { and rubber bands. }\end{array}$ & $\begin{array}{l}\text { Students can sequence } \\
\text { integers and compare their } \\
\text { quantities (viz. greater, } \\
\text { less, or equal). }\end{array}$ & $\begin{array}{l}\text { Students can sequence and } \\
\text { compare integers by giving } \\
\text { ideas regarding the } \\
\text { stimulus given. }\end{array}$ \\
\hline $\begin{array}{l}\text { Addition and } \\
\text { subtraction of } \\
\text { integers }\end{array}$ & $\begin{array}{l}\text { Collect the marbles } \\
\text { and rubber bands } \\
\text { freely. }\end{array}$ & $\begin{array}{l}\text { Play marbles and } \\
\text { rubber bands and list } \\
\text { the results of the games } \\
\text { in each session. }\end{array}$ & $\begin{array}{l}\text { Classify the number } \\
\text { of marbles and rubber } \\
\text { bands and make them } \\
\text { into mathematical } \\
\text { symbols. }\end{array}$ & $\begin{array}{l}\text { Generalize the } \\
\text { concept of addition } \\
\text { and subtraction. }\end{array}$ & $\begin{array}{l}\text { Students can do the } \\
\text { addition and subtraction } \\
\text { operations of integers } \\
\text { properly and correctly. }\end{array}$ & $\begin{array}{l}\text { Students can interpret the } \\
\text { addition and subtraction } \\
\text { operations of integers. }\end{array}$ \\
\hline $\begin{array}{l}\text { Multiplication } \\
\text { and division of } \\
\text { integers }\end{array}$ & $\begin{array}{l}\text { Gather marbles and } \\
\text { rubber bands to } \\
\text { group them together. }\end{array}$ & $\begin{array}{l}\text { Count/decompose the } \\
\text { number of marbles and } \\
\text { rubber bands collected } \\
\text { using certain rules. }\end{array}$ & $\begin{array}{l}\text { Count/decompose the } \\
\text { number of marbles } \\
\text { and rubber bands in a } \\
\text { group using a table. }\end{array}$ & $\begin{array}{l}\text { Generalize the } \\
\text { concept of } \\
\text { multiplication and } \\
\text { division of integers } \\
\text { in mathematical } \\
\text { symbols. }\end{array}$ & $\begin{array}{l}\text { Students who can perform } \\
\text { the multiplication and } \\
\text { division of integers } \\
\text { properly and correctly. }\end{array}$ & $\begin{array}{l}\text { Students can interpret the } \\
\text { operation of multiplication } \\
\text { and division of integers by } \\
\text { giving ideas regarding the } \\
\text { stimulus given. }\end{array}$ \\
\hline $\begin{array}{l}\text { Mixed count } \\
\text { operations }\end{array}$ & $\begin{array}{l}\text { Collect marbles and } \\
\text { rubber bands freely } \\
\text { in a variety of } \\
\text { groups, both units, } \\
\text { and bonds. }\end{array}$ & $\begin{array}{l}\text { Count the results of a } \\
\text { collection of marbles } \\
\text { and rubber bands in } \\
\text { various simulations. }\end{array}$ & $\begin{array}{l}\text { List counts in tabular } \\
\text { form. }\end{array}$ & $\begin{array}{lr}\text { Find the rules } \\
\text { mixed } & \text { count } \\
\text { operation } & \text { of } \\
\text { integers } & \text { in } \\
\text { mathematical } & \\
\text { symbols. } & \end{array}$ & $\begin{array}{l}\text { Students can perform the } \\
\text { mixed count operations of } \\
\text { integers properly and } \\
\text { correctly. }\end{array}$ & $\begin{array}{l}\text { Students can interpret the } \\
\text { mixed count operations of } \\
\text { integers by giving ideas } \\
\text { regarding the stimulus } \\
\text { given. }\end{array}$ \\
\hline $\begin{array}{l}\text { Word problems } \\
\text { related to } \\
\text { integers }\end{array}$ & $\begin{array}{l}\text { Playing marbles and } \\
\text { rubber bands } \\
\text { according to the } \\
\text { specified game rules. }\end{array}$ & $\begin{array}{l}\text { List the game results } \\
\text { and classify them into } \\
\text { arithmetic operations. }\end{array}$ & $\begin{array}{l}\text { Transforms the } \\
\text { results of the game } \\
\text { into sentences } \\
\text { containing } \\
\text { problems. }\end{array}$ & $\begin{array}{lr}\text { Turn } & \text { task } \\
\text { instructions } & \text { into } \\
\text { word problem } \\
\text { solving structures. }\end{array}$ & $\begin{array}{l}\text { Students can solve } \begin{array}{r}\text { word } \\
\text { problems related } \\
\text { Integers. }\end{array} \text { to } \\
\end{array}$ & $\begin{array}{l}\text { Students can provide } \\
\text { opinions and solutions to } \\
\text { the problems given and be } \\
\text { able to provide } \\
\text { explanations for the } \\
\text { answers given. }\end{array}$ \\
\hline
\end{tabular}




\section{Results}

\section{Sub concept 1: negative integers}

Early understanding of the integer concept was revealed through questions related to natural numbers and their calculation operations. All participants can give whole number examples, but some of them make additional mistakes. Andin, Anto, and Galang were able to add 78 and 26 correctly, while Lila and Rani had the wrong understanding of the numbers' place values. Rani thinks that the addition of 90 and 14 results in 914 because they are combined. This arises as a result of the term "compounding" which is often used to represent the meaning of addition. Merging is understood as an attempt to unify digit numbers regardless of the place value.

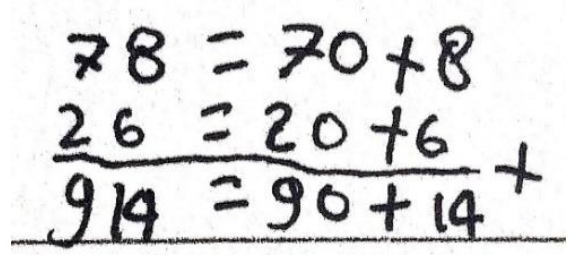

Figure 1. The sum solution was given by Rani

The next part is to introduce participants to negative integers. Initially, most students will have the difficulty interpreting negative numbers. This can be traced back to Andin's thought process, who answered 3 plus 4 easily, but experienced confusion when the question became 3 minus 4.

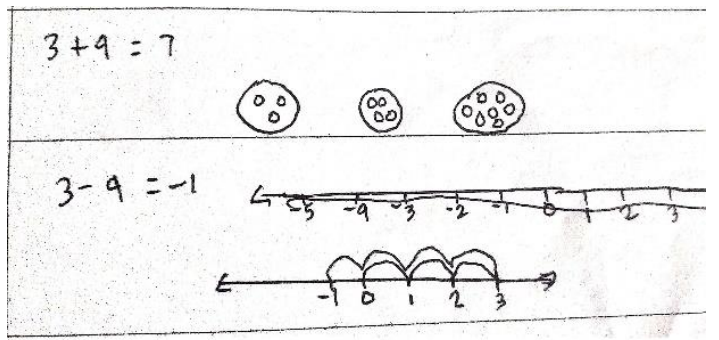

Figure 2. Andin's attempt to interpret negative numbers

Researcher: Why did you draw three small circles and four small circles inside the circle?

Andin: The question is asked to be added up, so I first draw the number of marbles and then combine them.

Researcher: If 3-4 can be done?

Andin: (Confused) I can't sir, it should be 4-3.

The above conversation shows that Andin tried to interpret the meaning of 3 minus 4 as the same as 4 minus 3 . However, her effort of drawing the number of marbles in a circle was not helpful enough, so Andin drew a number line. Initially, Andin put the point at 0 then moved to the right 3 steps, then moved to the left 4 steps, but she found that there were no numbers to the left of 0 so she, wrote one number which was marked negative. It was not easy for Andin to believe that 3-4 results in negative numbers. However, playing marbles helped Andin to get involved and try to construct the meaning of negative numbers.

Participants performed the instructions well and knew the number of marbles they were playing with. In the first session, Anto had won 3 marbles so that the number of marbles he had was 7. Anto was asked to write down the number of marbles he has won from the initial number of marbles. Meanwhile, Rani initially had 3 marbles but at the end game, Rani 
borrowed 1 marble from Lila. Here, the concept of negative integers began to emerge, and each participant investigated the difference in the game results between Anto and Rani. Andin understood that the initial number of marbles Anto had was 7-3 which is 4 marbles. The nature of reversibility was well understood by Andin and she could investigate the number of objects before the operation. The inverse property was used by Andin to identify the number of marbles held by each participant. Four more marbles were spent by Rani than the initial marble she had, so she had to borrow from Lila. Therefore, the borrowed marble could not be considered as Rani's marble. The object quantity of the borrowed proceeds was understood as a negative number and Andin realized that 3-4 is -1.
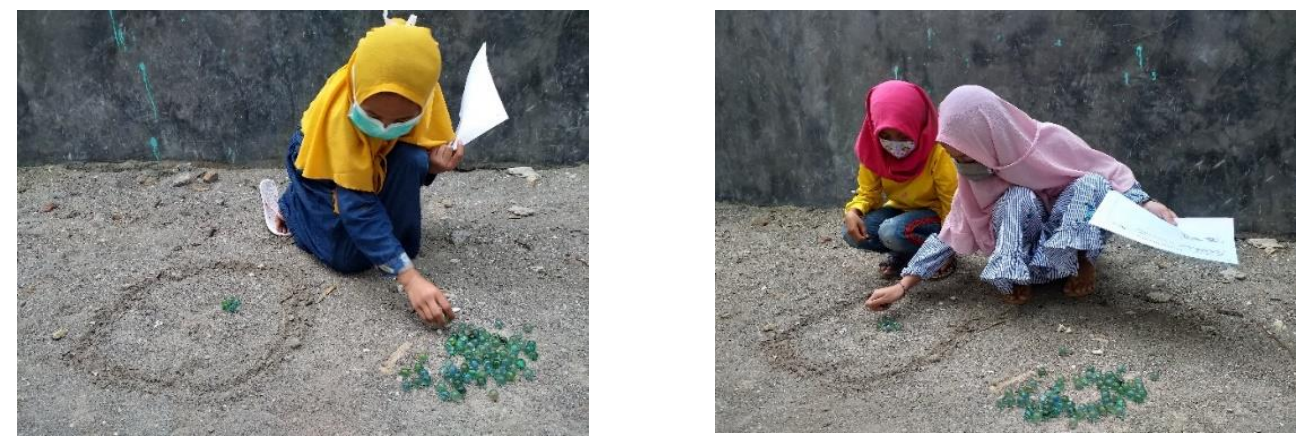

Figure 3. Participants play marbles and wrote down the results of the game

The results of game session 1 were continued for game session 2 and all participants were asked to write down their mathematical form. Lila and Rani were identified to be less able to write the use of mathematical symbols for each game situation properly. Lila and Rani had a difficulty understanding the meaning of winner or loser based on the outcome of the game as an addition or subtraction operation. This situation shows that there was a lack of words in understanding the problem so Lila and Rani required intervention in the form of using words that are relevant to their learning experience. Instructions were given to Lila and Rani that for each marble won is the sum of positive numbers, and vice versa if there is a loss. The game was carried out for 3 sessions and the final results are shown in Table 3.

Table 3. Game results in each session

\begin{tabular}{lllll}
\hline & \multicolumn{2}{l}{ Number of Marbles } & & \\
\cline { 2 - 5 } & Initially & Session 1 & Session 2 & Session 3 \\
Andin & 4 & 5 & 6 & 8 \\
Anto & 4 & 7 & 7 & 9 \\
Galang & 3 & 1 & -1 & -2 \\
Lila & 4 & 5 & 5 & 7 \\
Rani & 3 & -1 & -1 & -4 \\
\hline
\end{tabular}

The results of the game show that Galang and Rani had borrowed marbles and generated negative numbers. All participants realized that Rani was the loser, followed by Galang, Lila, Andin, and Anto were the winners. This situation shows that all participants understood the sequence of integers and had found the meaning of negative numbers. This helped them distinguish positive and negative numbers and the order in which they expressed their quantities. Furthermore, participants were asked to sort the numbers $-1.000,-256,-89,67,89$, and 345. All participants understood the meaning that the greater the quantity in negative numbers, the smaller the value and vice versa for positive numbers. 


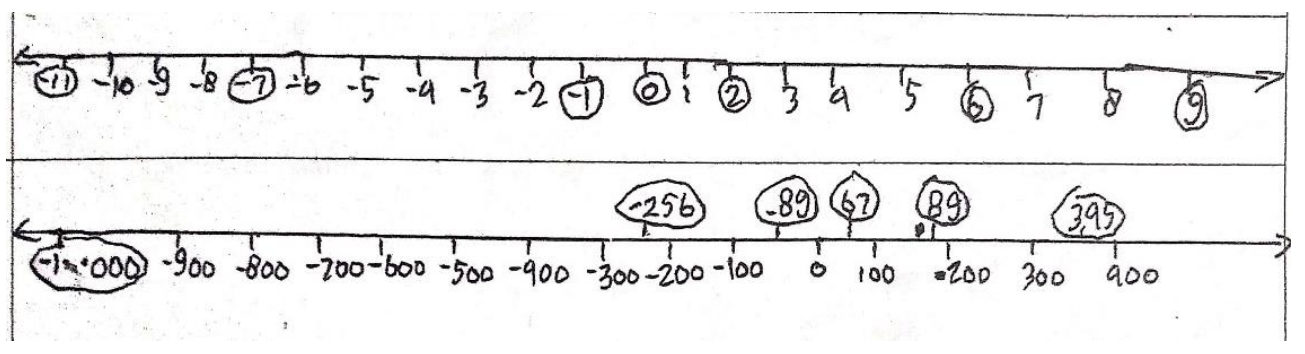

Figure 4. Andin places the number on the number line

Researcher: How do you determine where the -1,000 and everything else is on the number line?

Andin: (Thinking) too long sir, a lot. But maybe it can be made -100, -200 until -1000.

Researcher: Then how do I determine the location of -256?

Andin: (Thinking) -256 between -200 and -300, so that's about here sir.

Andin understood the sequence of numbers well and she could place large numbers. The first step that Andin took was determining the zero position on the number line then she placed the positive numbers on the right and the negative numbers on the left sequentially. Andin understood the meaning of place value and quantity which helped her estimate the position between two numbers. In general, the marble game helped Andin construct a mean understanding of negative integer quantities and apply them to the number line. Furthermore, other participants seemed not able to make the transition properly, such as mistakenly estimating the proportions where the numbers were located.

\section{Sub concept 2: sequence integers}

Understanding the prerequisites was assured by asking several questions, such as finding out which number is located 6 steps before 3 . This was intended as recognition in the previous HLT. Participants can understand the context through playing marbles. Participants can also use a number line as a visualization of their idea. Each participant had different ideas that arose as a result of the question sentence interpretation. Galang took 6 marbles then determined 3 marbles to produce 3. Lila took 3 marbles then she took 6 marbles to produce 9 . Andin and Anto took 3 marbles then, but they took 3 more marbles. However, they did not combine them in the box and thought of it as a loan yield so the result is -3. Rani did not provide an adequate response to regulations. It seems that Andin and Anto had a more plausible way. Anto did not even immediately understand that the number he was looking for was the number to the left of 3 . At first, Anto misunderstood the instructions and realized it again after rereading them. Anto understood that the meaning of the problem was equivalent to taking 6 marbles from the 3 available marbles. However, it did not make any sense so Anto collected 3 marbles each in different places.

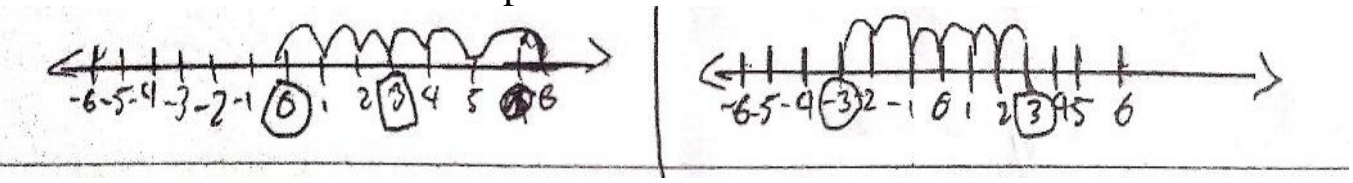

Figure 5. Anto's way tracing location of the numbers

Apart from using marbles, researchers also used rubber bands to ensure an understanding of the integer sequence. Yellow rubber bands represent positive numbers, and red rubber bands represent negative numbers. Participants collect groups of marbles and rubber bands freely to 
use in the game. Yellow and red rubber bands were used so that participants did not experience confusion regarding the rules of the positive and negative numbers. Furthermore, participants choose to play marbles or rubber bands and recorded each game result in the table. Rules of play together on the type of game played. During the game, the researcher gave the order not to combine marbles and rubber bands or exchange them. This is meant for the participants to not think that the number of marbles and rubber bands can be operated. For example, 3 marbles added by 2 rubber bands to the result in 5 . The collected data were then arranged from largest to smallest. All participants responded that the order was Andin, Rani, Lila, Galang, and Anto. Participants did not realize that there were 2 games where the results could not be combined. The researcher reiterated that the marbles and rubber band games each had their own rules so that Andin, Anto, and Lila realized that there were two winners in this game. Galang and Rani seemed to have difficulty interpreting these differences and finally found that they were not involved in the same game. The scenario in this activity provides an understanding to participants that numbers represent a context so that they cannot be carelessly used.

The formalization of the number sequence was done by asking participants to compare the numbers -977 and -875 . Previous studies have left quite clear traces on each participant to easily give the response that $-977<-875$. Each participant has a learning trajectory that the negative number with the largest number is the smallest so that this stage can be easily understood.

\section{Sub Concept 3: Addition and subtraction of integers}

Participants' understanding about the addition and subtraction of integers was carried out by proposing $1781+1338$ and $2.466-2.107$. In the addition case, all participants had the right way to get a solution. Rini performed the long-term operation she had used and showed better performance than the previous HLT. On the other hand, Rani erred in the subtraction case by subtracting 6 and 7 without involving place values. Rani did not understand that 6 minus 7 can borrow one ten, resulting in 16 minus 7, and then the remaining fifty to be subtracted by zero tens. Supposedly, Rani was able to get a solution of 359, but the result she got was -361. Rani could sequentially add integers, but could not subtract integers because she was confused about how to subtract 6 and 7. It appeared that Rani did not fully understand the meaning of place values in the subtraction operation. Rani experienced many misconceptions by subtracting thousands and hundreds first just as she did with addition. In the end, errors arose because the unit value could not be operated directly, so Rani assumed that the result of the reduction was negative. Meanwhile, Andin, Anto, and Galang used the regular subtraction method and came up with the right solution.

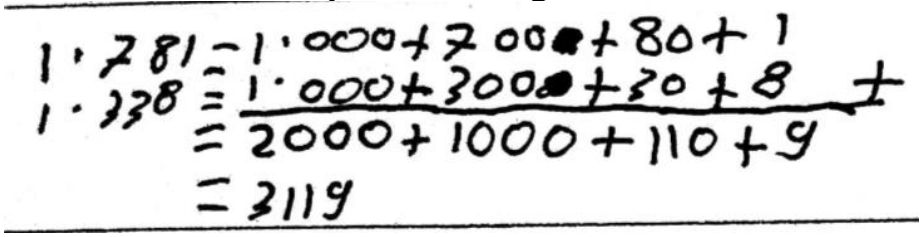

Figure 6. Rani did the compound addition

The place-value rule is a basic concept in numeric count operations, but this concept is often only conveyed in rote form. Researchers show the addition rules starting from the unit place value, tens, and so on using a rubber band. For example, $16+15$ can be done by taking 10, 6, 10 , and 5 rubber bands. 6 rubber bands are combined with 5 so that the result becomes 11 , then combined again with 20 other rubber bands, and finally reaching a total of 31 . This 
activity helps participants understand the meaning of place values in count operations and the reasons for storing place values in each higher unit.

Participants were asked to take a red and yellow rubber band to play with. Each of them started counting the number of rubber bands taken and wrote them down (if you take 10 yellow rubber bands then write 10 and if you take 10 red rubber bands, write -10). The yellow rubber band is played for the first time and if it runs out then you can use the red rubber band. An important part of this game is that the participants can grasp the meaning of playing yellow and red rubber bands. If a participant has a yellow and red rubber band then the scores are considered neutralizing each other. For example, there are 10 red rubber and 10 yellow rubber means the value is 0 . Therefore, all participants played with a value of 0 then in each game session, the results of the rubber bands were calculated. Andin and Anto understood these instructions by writing down the change in the number of rubber bands in each session as a result of addition or subtraction operations. Lila, Galang, and Rani could only write down each change in the number of yellow rubber bands and ignored the red rubber bands. All participants wrote their game results in a list in the table. The results of this game were then formed mathematically.
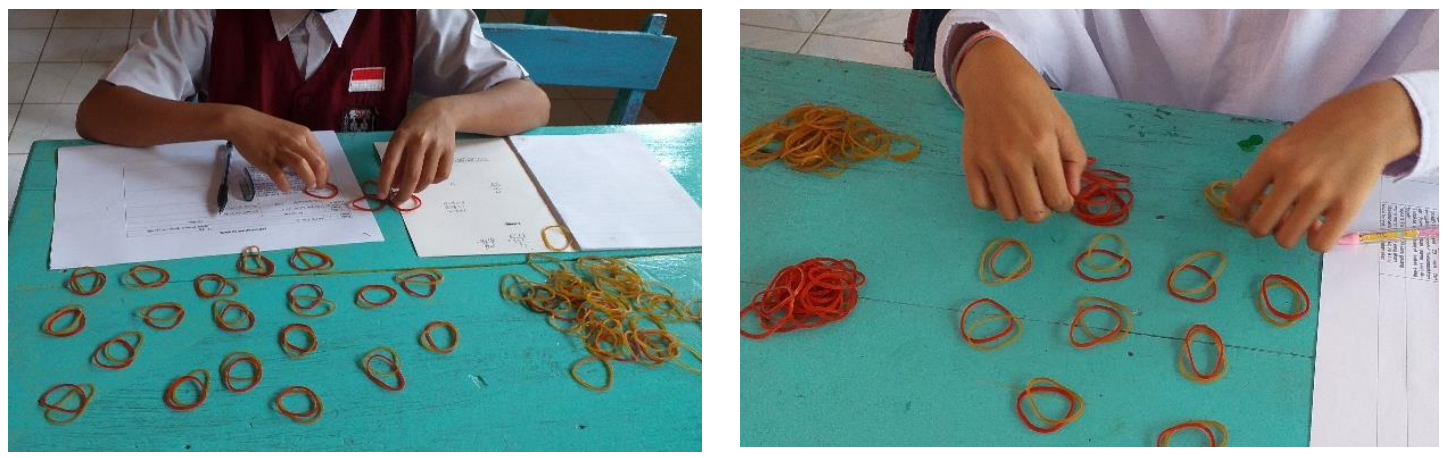

Figure 7. Participants add integers using rubber bands

The change in the number of rubber bands in each session can be written in the form of the integers sum. For example, Andin wrote the number of rubber bands going from 24 to 18 as 24-6, then 18 to 5 as $18-13$, and finally from 5 to -6 as $5-11$. Andin realized that she had spent 30 rubber bands in the game that she earned from $24-(-6)$, a sign that is less interpreted as a result of losing in each session. Galang wrote the result of the game in each session with the loss in subtraction. Session 1 was written as 20-12 yields 8, then session 2 was written as 8 (- 8) to produce 16 rubber bands. Galang initially did not understand the meaning of the result, but Galang realized that the remaining red rubber band he had was a result of 15-8 and the initial agreement that the red rubber band was a negative number. In session 3 , Galang was confused to write down the remaining sum 2 red rubber bands he had. However, Galang knew that a red rubber band is a negative number, so writing $-7-(-5)$ gives -2 . Furthermore, Anto in session 2 won 4 red rubber bands so that it can be written $-30+(-4)$ to -34 . The activities carried out provided important information regarding the addition of integers, i.e., $a+(-b)=a-b$ and $a-(-b)=a+b$. Furthermore, for $a>b$, participants could identify the result of $a-b$ is positive and vice versa if $b-a$, then the result is negative from $a-b$.

$$
(1.000+34)-(1.000+47)=-13
$$

Figure 8. Lila subtracts integers 
The researcher then asked the participants to determine the results of 1.034-1.047 as an extension of the thousand-number addition concept. This problem was given to test participants' understanding of place values, and integers subtraction. Participants observed that the values of thousands, hundreds, tens, and units have relevance to determining the greatest quantity. Lila tried to parse the number as the sum of 1.000 and simplified it while taking yellow and red rubber bands. Lila neutralized each rubber band of a different colour and left 13 red rubber bands. Lila realized that $47>34$, then the result will be negative from the result of subtracting 47 and 34 , which is -13 .

\section{Sub Concept 4: Multiplication and division of integers}

The concept of multiplication and division is closely related to the concept of repeated addition and generally, this method is the most widely used in the learning process. However, the analogy used to capture multiplication concept using repeated addition has a drawback, especially in the multiplication of negative integers. Moreover, in the concept of division, it is generally considered the multiplication inverse operation so it requires reversibility. Participants' understanding was identified using the $6 \times 5$ multiplication and 96:6 division task. Andin and Anto completed the task using repeated addition for multiplication and repeated addition for the division. Galang and Rani did the multiplication by memorizing, but for the division task, they could not complete it. Lila completed the multiplication task by writing $6 \times(10 / 2)=60 / 2=30$, while the division task was done in a compound manner, but it was not correct. Each participant had a different way they considered the most logical. To facilitate the transition, before learning begins, the researcher presented several rubber band game rules. Participants were asked to collect yellow and red rubber bands, then group them into ties. Participants made rubber band ties that were used for games. Researchers instructed them to make 3 pieces of ties for free using yellow and red rubber bands. Furthermore, participants were asked to list the number of rubber bands they used to make ties.
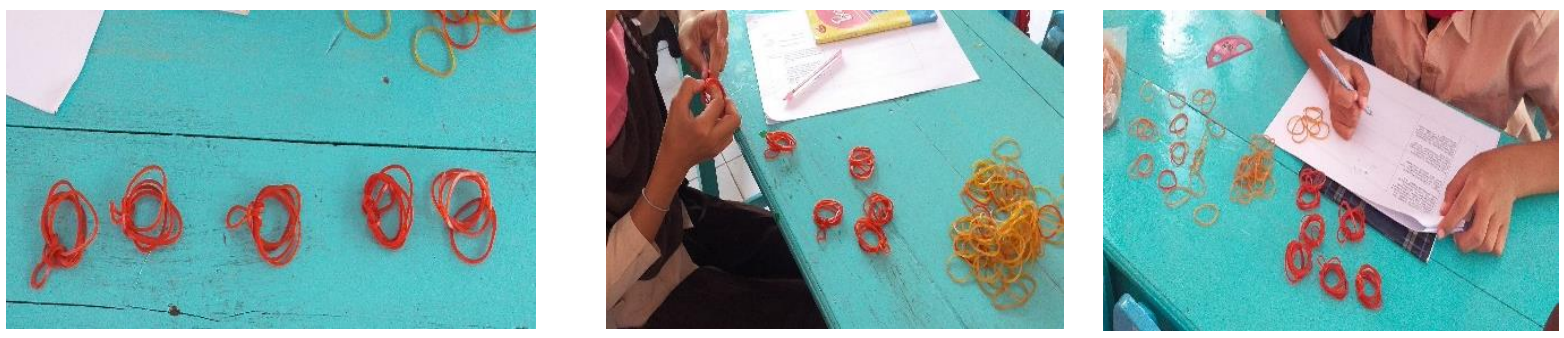

Figure 9. Participants made tie rubber bands to multiply integers

Participants listed each of rubber band that were formed independently. Anto made five ties, each consisting of five red rubber bands. The number of rings in each band must be the same, then Anto counted the total number of rubber bands. Anto understood that the number of his red rubber bands is 25 which can be written as repeated additions. Each participant was asked to freely make ties and register them, the results of this activity can be seen in table 4 . 
Table 4. Number of rubber bands for made ties

\begin{tabular}{lllllll}
\hline & \multicolumn{2}{l}{ Number of yellow rubber bands } & \multicolumn{3}{c}{ Number of red rubber bands } \\
\cline { 2 - 7 } & Ties 1 & Ties 2 & Ties 3 & Ties 1 & Ties 2 & Ties 3 \\
Andin & 15 & 8 & 10 & -10 & -24 & -10 \\
Anto & 20 & 24 & 14 & -9 & -25 & -8 \\
Galang & 16 & 12 & 15 & -16 & -20 & -6 \\
Lila & 12 & 32 & 20 & -18 & -16 & -30 \\
Rani & 10 & 8 & 18 & -12 & -16 & -12 \\
\hline
\end{tabular}

The data in table 4. is described as the sum of the rubber band ties. For example, Andin in bond 1 had a total of 15 rubber bands consisting of 3 ties each containing 5 rubber bands so that it can be written as $15=5+5+5$. Lila made 5 ties of 6 red rubber bands each. Each tie is symbolized by -6 , so the total number of rubber bands is indicated $(-6)+(-6)+(-6)+(-6)+(-6)$ $=-30$. All participants can write the sum of these ties as repeated addition.

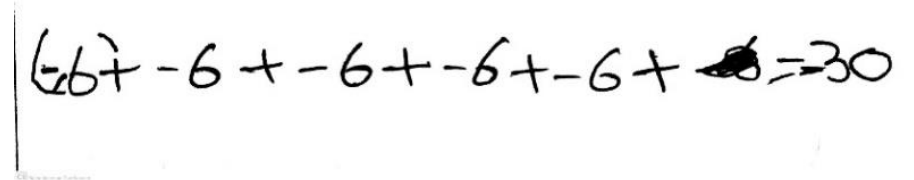

Figure 10. Lila wrote the formal form

Conversely, division is the process of breaking down a bunch of rubber bands into equal parts. Galang collected 12 yellow rubber bands to group them into 6 ties. The instructions given made Galang break down each batch of rubber bands by 2. Initially, Galang wrote 12 minus 2 , the result was 10 , then deducted each result by 2 until it ran out. The number of subtractions done is recorded as the ties number, whereas the bunch of rubber bands in each band is the division result. The method that was used by Galang was not always effective. Sometimes he had to try repeatedly and even the results he got did not produce a solution. However, the path that Galang constructed was very helpful in finding the relationship between multiplication and division.

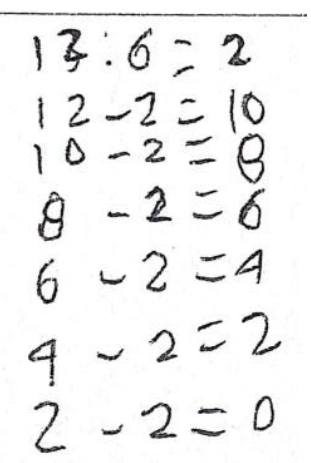

Figure 11. Galang wrote repeated subtraction

Furthermore, this repeated addition procedure is gradually transformed into the multiplication form. The process of repeated addition transformation as a form of negative multiplication appears to be more complex. For example, the multiplication of -2 by -2 would be modelled as an iterative addition. The challenge is that the participants must show that -2 can add up to -2. Of course, this does not make sense. Researchers helped participants think critically and have to courage to develop the repeated addition concept. Participants already know that -2 times 2 means $(-2)+(-2)$ or -4 . If the multiplier -2 is decreased from every one unit then the value always increases 2 . If -2 is multiplied by 1 then the result is -2 , and if -2 is multiplied by 0 the result is 0 , even if -2 is multiplied by -1 then the result becomes 2 . Finally, when -2 
is multiplied by -2 the result becomes 4 . This process simultaneously expands the multiplication explanation between negative numbers to produce positive numbers. Researchers helped participants construct a formal form of the multiplication of numbers concept and extended it to various examples as shown in table 5.

Table 5. Expansion of the multiplication integers concept

\begin{tabular}{lllllllll}
\hline Formal & Mode for & Result & Formal & Mode for & Result & Formal & Mode for & Result \\
\hline $3 \times 5$ & $5+5+5$ & 15 & $3 \times 3$ & $3+3+3$ & 9 & $-2 \times 3$ & $-(3+3)$ & -6 \\
$2 \times 5$ & $5+5$ & 10 & $3 \times 2$ & $3+3$ & 6 & $-2 \times 2$ & $-(2+2)$ & -4 \\
$1 \times 5$ & 5 & 5 & $3 \times 1$ & 3 & 3 & $-2 \times 1$ & $-(2)$ & -2 \\
$0 \times 5$ & 0 & 0 & $3 \times 0$ & 0 & 0 & $-2 \times 0$ & 0 & 0 \\
$-1 \times 5$ & $-(5)$ & -5 & $3 \times(-1)$ & $(-1)+(-1)+(-1)$ & -3 & $-2 \times(-1)$ & $-(-1-1)$ & 2 \\
$-2 \times 5$ & $-(5+5)$ & -10 & $3 \times(-2)$ & $(-2)+(-2)+(-2)$ & -6 & $-2 \times(-2)$ & $-(-2-2)$ & 4 \\
$\vdots$ & & & $\vdots$ & & & $\vdots$ & & \\
\hline
\end{tabular}

The reversal procedure for the division operation was done by untying the rubber band ties equally. Anto broke down the 1 bond into 3 equal bonds totalling 3 rubber bands each, so he wrote -9: 3 results in -3 . Anto understood that the broken down of the red rubber band ties is red so the result is negative. Reversibility was a challenge for Galang, Lila, and Rani. To make it easier for participants to understand reversibility, the researchers conducted simulations on rubber band ties. Each participant understood that every untied red rubber band will still produce a red rubber band, which means that a negative number divided by a positive number results in a negative number. Conversely, if the red rubber band is divided by a negative number, to make the context meaningful, the rubber band is changed to yellow so that it is concluded that a negative number divided by a negative number produces a positive number. The formalization of this activity produces important relationships, i.e., $\mathrm{a} \times \mathrm{b}=\mathrm{c}, \mathrm{a} \times(-\mathrm{b})=-\mathrm{c},-\mathrm{a} \times \mathrm{b}=-\mathrm{c},-\mathrm{a} \times(-\mathrm{b})=\mathrm{c}, \mathrm{b}=\mathrm{c} \div \mathrm{a},-\mathrm{b}=-\mathrm{c} \div \mathrm{a}, \mathrm{b}=-\mathrm{c} \div(-\mathrm{a})$, and $-b=c \div(-a)$.

\section{Sub Concept 5: Mixed count operations of integers}

Mixed count operations are basic arithmetic concepts that often lead to misconceptions. The causes were identified in the task given to participants to complete $10+2 \times 5-4 \div 2$. Lila began to complete the multiplication first, then Lila added the product, then subtracted, and finally divided. Anto completed it sequentially from left to right, while Andin, and Galang began from multiplication then subtraction, division, and finally addition. Rani started doing multiplication then subtraction, addition, and finally multiplication. Although mixed count operations often appear in various arithmetic topics, the variation in the responses given by the participants indicates that there is a thought process that is not solid. All participants know that in arithmetic operations, the process starts with parentheses, then multiply/divide, and finally add/subtract. However, the participants did not understand the reasons behind the arithmetic procedure. Participants solved the mixed count operation in different ways because they followed the intrusion regardless of the procedures they already knew.

Solving mixed count operations problems involves more complex abilities and requires participants to previously master HLT. Choosing addition or subtraction to solve first is very context dependent. Likewise, multiplication and division are operations that have a higher hierarchy than addition or subtraction. Therefore, if there is no context, these operations must be prioritized to be completed first. The mixed count concept requires instructions that facilitate the participants to use various count operations. The activity begins by asking 
participants to collect rubber bands in 4 different boxes in varying numbers. The first box contains yellow individual rubber bands, the second box contains red individual rubber bands, the third box contains yellow bonding rubber bands, and the fourth box contains red bonding rubber bands. The collected marbles are then counted and written in mathematical symbols.

The addition of rubber bands is done by collecting rubber bands of the same colour and then pairing them with different rubber bands colours to make them neutral. The unpaired remainder rubber bands are the actual amount. This process provides participants with an understanding that the amount they earn is following the count operation basic rules. Participants begin to understand that in mixed count operations, multiplication is more than addition and decreases. Furthermore, a simulation is carried out by grouping a bunch of rubber bands into equal bonds and addition them together. A collection of yellow or red rubber bands is in box 1, then the rubber bands in box 2 are grouped equally into ties, then the bonds formed in box 2 are added to the rubber bands in box 3 and 4 which are red and yellow.

Participants could understand that division is a decomposition form of a set so that the mixed count operation must be completed first. An exception is given if the situation requires the addition/subtraction operation to be completed first. This situation is simulated in the sequential activities form so that to obtain the final result, the problem must be completed from the earliest calculation operation. The simulation process helps participants make the transition from the participatory to the anticipatory stage. The sequence of mixed count operations is gradually coordinated in the word problem solving process. Simulation games help participants use count operations to solve problems. For example, in addition and subtraction, the participants know that there has been a change in quantity in units while multiplication is a repeated addition of quantities and division is the breakdown of the whole unit into equal parts. Participants use a tiered process in solving the mixed count operation problem according to the sequence obtained during the simulation. However, the stage of participant formalization cannot be further ascertained on issues outside the context of traditional games involving more complex situations.

\section{Sub Concept 6: Word problem solving of integers}

Using the integers concept to solve problems is at the learning heart. The difficulty that is often experienced is the ability to model situations into formal mathematical forms. Using learning trajectories through experiential activities is very helpful for participants in making the transition from informal mathematics to formal forms. For example, participants are asked to determine the number of marbles that are spent in the game. Participants write the winning result as an addition operation and defeat as a subtraction operation. For multiples of the winning result, use the multiplication operation, and decompose the same number of marbles using the division operation. The transformation of the word problems used in traditional games makes it easy for participants to formalize.

The problem given is an open situation so that participants can construct their learning trajectory. The researcher proposed a box containing 6 marbles and then asked the participants to make a game scenario to produce 10 marbles. Andin, Anto, and Lila wrote the simplest scenario, i.e., winning 4 consecutive marbles in the game. Rani formed a scenario by winning 2 game sessions with 2 marbles each. Galang made a more complex scenario, i.e., losing half of the marbles in session 1, then winning sessions 2 and 3, and getting the last 1 
additional marble. Participants used the experience of playing marbles as a context that could be used to solve problems. Various possibilities can be an offer for the solution to the problem given.

The ability of participants to solve word problems is extended to various situations. The next case was by giving a problem, Adi had 200 marbles then his friend took 30 items, the rest was used to play and managed to win 25 items. Because Adi was no longer allowed to play marbles, Adi divided his marbles among his 5 friends equally. Determine how many marbles Adi's friend gets! The problems given do not require participants to carry out simulations, but rather use the ability to model story questions into a mathematical form. Participants must understand the situation related to the information provided, the problems faced, and how to solve them. Therefore, participants began to slowly read the text on the questions and put the storyline in order. Andin wrote down the number of marbles first and began to think about the meaning of the word "take". In the previous HLT, the word took meant that something was reduced from its quantity, so Andin subtracted 200 by 30. Furthermore, there was the word "win" which was interpreted in the game of marbles as an increase, so Andin wrote 200-30+25. Sentence determines the solution to this problem because it is related to which operation will take precedence. Andin understood that the operation she would use was division, but if she wrote $200-30+25: 5$, then the solution is irrational. The sequence of events led Andin to a decision that required her to make parentheses. Andin understood that the marbles to be divided were the result of the marble game, which was a separate event from the process of dividing the marbles. The learning trajectory constructed by Andin shows the ability to transform word problems into a mathematical model to guide her to a logical solution.

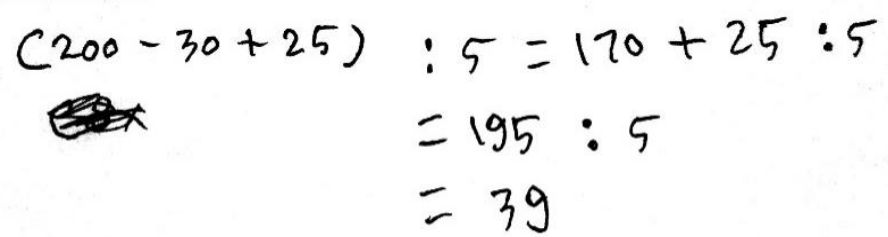

Figure 12. The work of Andin word problem solving at integer

The second problem given was related to buying and selling activities, i.e., The mother had IDR 100.000, - which would be used to buy daily necessities and pocket money for her children. The first child receives IDR 12.000, the second child gets half the pocket money of the first child, and the third child gets half the allowance for the second child. The remaining spending money is used to buy fish and rice. The price of rice is IDR. $8.000 / \mathrm{kg}$ and the price of fish is IDR 10.000/head. Determine the possible amount of fish and rice that mom can buy! Participants read the text over and over again to understand this issue. There are many cognitive abilities required in addition to count operations, such as understanding proportions, sequencing, comparisons, and remaining division. Many participants experienced confusion, but Andin did a great in solving this problem. 


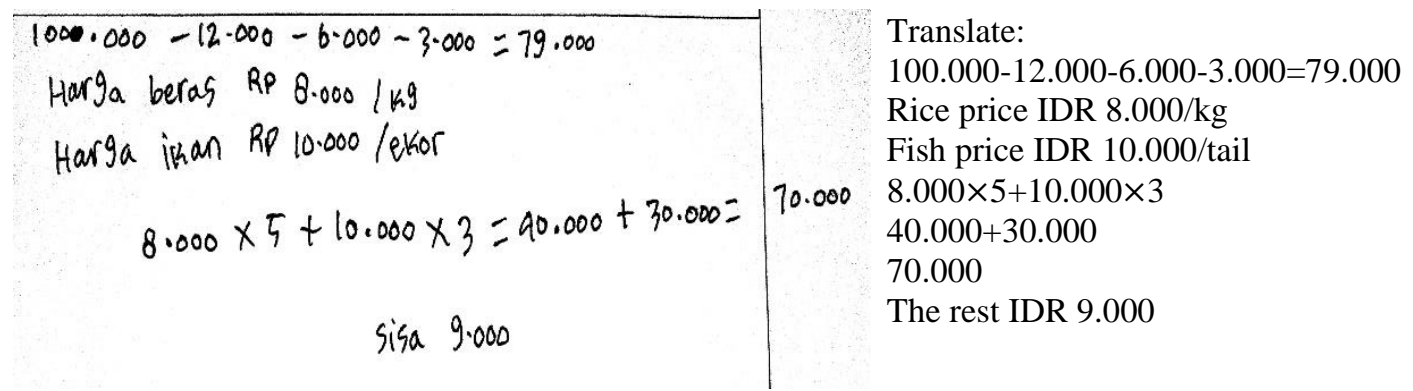

Figure 13. The work of Andin word problem solving at integer

Initially, Andin wrote the amount of money and modelled the situation into successive subtraction operations. The word "use" was understood by Andin as the word equivalent to "take". Furthermore, the word "half" was understood as a proportion of $1 / 2$ of the amount of money for the first and second children. The proceeds from giving pocket money were considered as the remaining money that would be used to buy rice and fish. The problem is determining how much rice and fish the rest of the money can buy. Andin assumed that the money could be used to buy $5 \mathrm{~kg}$ of rice and 3 fish, but the result was still IDR 9.000 left. The solution given was quite logical and she could calculate the remainder of the division. Anto thought that this money must be used up, but the variations he got were not feasible. Meanwhile, Galang, Lila, and Rani experienced an error at the beginning of understanding the problem, so they were unable to find the right procedure. There were many possible solutions to this problem, but the participants were not able to see the solution.

\section{Discussion}

Integers have many connections with the student's learning experience. Traditional games are examples of numeracy activities carried out by students in coastal communities. Each student demonstrates a unique way of playing that is connected to the counting. For example, Andin used a method of neutralizing different colour rubber bands to count the number of negative integers, Anto classified non-owned marbles in the game as loans, and Lila counted the number of red rubber bands repeatedly to find the meaning of multiplying negative integers. Participants used number lines to verify how to count in the game to facilitate the transition process. Connecting the concept of integers with culture helps students make better interpretations of calculating operations (Sun, 2018). For addition and subtraction operations, elementary school students generally use direct calculations by modelling the actions or relationships described in the problem (Stephan \& Akyuz, 2012; Verschaffel et al., 2020). This is in line with the findings of this study which showed that participants quickly used the addition operation for each increase in marbles and the subtraction operation for each loss in the game. Involving students interactively through various activities using media can foster the ability to recognize object numbers (Widodo et al., 2021). However, participants at the beginning of the lesson were not careful with the meaning of place values, so they carried out arithmetic operations carelessly. Traditional play activities provide a fundamental understanding of the significance of place values. The base 10 decimal system which is used as a universal number system represents a place value system for each arithmetic operation (Howe, 2018). Therefore, place value is an important concept that must be instilled in students in teaching integer arithmetic operations. 
Furthermore, the students' ability to compare and sort objects was more successful than other items (Clements et al., 2011). In line with the results of this study, the participants were more familiar with the sub-concepts of sequence and integer comparison than the other subconcepts. The comparison procedure is done by comparing the place value sequence of the largest part of a number, then the largest of the sequence states the larger quantity (Howe, 2018). Participants realized that the concept of order and comparison of positive and negative Integers has opposite rules. The nature of the inversion is a mental operation that can be used by participants to make the transition from the participatory to the anticipatory stage.

Traditional games are an effective tool for diagnosing student misunderstandings through various simulations and problem modelling techniques. Model-based problem solving is a conceptualization of mathematical relationships with basic arithmetic word problems which have important features related to modelling, higher-order thinking, and algebraic readiness (Xin, 2018). The transition process is largely determined by the sequence of tasks and learning situations that allow participants to express instructions into mathematical symbols (Gravemeijer, 2004). At the beginning of the lesson, the teacher uses situations that are expressed into words to represent arithmetic operations (Csíkos \& Szitányi, 2020). Giving assignments in the form of real problems faced by students is a key idea to find the learning needs needed while achieving learning objectives (Isoda, 2010). Making concept connections provides an opportunity to change the meaning of the Integers concept underlying the original problem and various other variations (Sun, 2018). Students may experience misconceptions in establishing connections between context and content domains. Diagnosing student misunderstandings in solving problems can provide more space to reveal where errors are located along the content trajectory and provide information about classroom interventions (Rakes \& Ronau, 2019).

Students solve word problems using various terms that are relevant to traditional games. For example, a directly additive word is understood as an addition operation or a word that is taken is assumed to be a subtraction operation. This method is effective enough to be combined with other strategies, such as using keywords, using images, working backward, guessing, and schematic instructions (Verschaffel et al., 2020; Xin, 2018). Solving word problems using simple strategies effectively increases student participation rates. Conversely, teaching strategies with long algorithms begin to be questioned if the solution to the problem can be solved in one step (Csíkos \& Szitányi, 2020). Problem-solving constructs consider students' experiences and anticipate their future strategies (Land et al., 2019; Özkubat et al., 2020).

Participants have various learning trajectories to understand integer word problems through traditional game simulations. The simulation provides an idea for transmitting the abstraction process from the participatory stage to the anticipatory stage. Triangulating data in the form of pictures, writing, and non-verbal movements can be used to summarize students' thoughts (Ellis et al., 2016). Anticipatory task is shown by the student's ability to call new abstractions without any activity being carried out (Simon et al., 2016). The process of internalizing actions by taking participatory support can result in heavier abstraction difficulties resulting in less relevant strategies and missed opportunities to apply them in various contexts (Weber, Walkington, \& Mcgalliard, 2015). This is in line with the findings of this study which showed that participants were confused in solving the last case in HLT 6. Contexts that are different from traditional games create internalization difficulties which result in a lack of anticipatory action. The difference in student performance in solving problems is also related to the numerical characteristics and different problem contexts (Elia, 2019). 
Participants in the task sequence show little anticipatory ability which is sometimes temporary. The ability to summon abstractions without engaging in activities tends to be difficult in different situations. This situation is experienced by participants in the subconcept of word problem solving where the context is beyond the scope of their reflective abstraction. Participants can reach the anticipatory stage, although the abstraction produced in each activity engagement only shows evidence of the participatory stage (Simon et al., 2016). The learning trajectory requires the attainment of an anticipatory stage that allows coordination of actions on previous sub-concepts.

Participants understand the forms of word problems and logical representations that allow solutions to emerge. For example, multiplication is often thought of as a representation of repeated addition and division as repeated subtraction (Verschaffel et al., 2020). However, the iterative addition approach to represent multiplication has much lack (Sun, 2018). Some of them are the inability of repeated addition to explaining the representation of multiplication of negative integers. Using traditional game simulations can help participants find the relationship between the concepts of addition and multiplication and their application to negative numbers. The multiplication properties procedure helps participants solve word problems related to mixed count operations. Participants apply associative and distributive properties as a means to invoke the solution of large value arithmetic operations. In addition, the location of the base place value has a close relationship with the distributive and associative rules that apply to multiplication (Howe, 2018).

Learning trajectories on integers is like constructing building blocks that reinforce each other. If participants are weak on the concept of addition/subtraction, then it is certain that participants will also be weak on the concept of multiplication/division, as is the case for higher concepts. Learning trajectories are built from a cognitive perspective that represents student identity, mathematical practice, and norms for the relationship between peers and teachers (Weber, Walkington, \& Mcgalliard, 2015). Care needs to be taken in assessing the problem-solving strategies used by students. Each solution has a trajectory of the learning experience that is independent, although it can be influenced by interventions in teaching. Teacher responses to problem-solving strategies used by students need attention so as not to produce biased assessments (Land et al., 2019).

\section{Conclusion}

Traditional games such as marbles and rubber bands are functional tools that can represent integer count operations. Playing is an activity often done by students in coastal areas and can be a learning activity in helping students construct an integers concept understanding. Learning activities are constructed following a game scenario, and students gradually discover concepts through task design. The learning process using the traditional game's context makes students realize that mathematical concepts appear in daily activities. Students can create learning trajectories from traditional games and solve word problems in different situations. Students construct learning trajectories starting from the free play stage, collecting data from the game results, making mathematical relationships, building concepts, and applying them to various problems. Further, students solve word problems with integers formed by finding negative integer concepts, sorting, and performing count operations on integers. However, students still need intervention from the teacher to carry out each step correctly, especially in counting operations with negative integers or problems involving large numbers. Some students have a dependence on traditional game tools so that it becomes an obstacle in solving more complex problems. The solving word problems process also 
requires the ability to identify word relationships that correspond to integer count operations. Students' ability to solve word problems must involve the construction of learning experiences included the strategies used to model situations into mathematical equations using contexts that are easy to understand. This study did not use a longitudinal study because the expected information is not the result of the intervention over a long period but develops naturally. The discussion of this research has not linked much to the formal concept formation process so that many factors that could potentially influence students' thinking in coordinating actions require further study. This information is very important to get an idea related to the form of instructions and behaviour that students might take when solving integer word problems.

\section{References}

Barrett, J. E., Sarama, J., Clements, D. H., Cullen, C., McCool, J., Witkowski-Rumsey, C., \& Klanderman, D. (2012). Evaluating and improving a learning trajectory for linear measurement in elementary grades 2 and 3: A Longitudinal Study. Mathematical Thinking and Learning, 14(1), 28-54. https://doi.org/10.1080/10986065.2012.625075

Carter, E., Rose, P., Sabates, R., \& Akyeampong, K. (2020). Trapped in low performance? tracking the learning trajectory of disadvantaged girls and boys in the complementary basic education programme in Ghana. International Journal of Educational Research, 100(December 2019), 101541. https://doi.org/10.1016/j.ijer.2020.101541

Clements, D. H., \& Sarama, J. (2009). Learning and teaching early math: the learning trajectories approach. Routledge.

Clements, D. H., Sarama, J., Spitler, M. E., Lange, A. A., \& Wolfe, C. B. (2011). Mathematics learned by young children in an intervention based on learning trajectories: A large-scale cluster randomized trial. Journal for Research in Mathematics Education, 42(2), 127-166. https://doi.org/10.5951/jresematheduc.42.2.0127

Csíkos, C., \& Szitányi, J. (2020). Teachers ' pedagogical content knowledge in teaching word problem solving strategies. ZDM, 52(1), 165-178. https://doi.org/10.1007/s11858-01901115-y

Dröse, J., \& Prediger, S. (2020). Enhancing fifth graders' awareness of syntactic features in mathematical word problems: a design research study on the variation principle. Journal Fur Mathematik-Didaktik, 41(2), 391-422. https://doi.org/10.1007/s13138-019-00153-z

Elia, I. (2019). Word problem solving and pictorial representations: insights from an exploratory study in kindergarten. ZDM. https://doi.org/10.1007/s11858-019-01113-0

Ellis, A. B., Ozgur, Z., Kulow, T., Dogan, M. F., \& Amidon, J. (2016). An exponential growth learning trajectory: students' emerging understanding of exponential growth through covariation. Mathematical Thinking and Learning, 18(3), 151-181. https://doi.org/10.1080/10986065.2016.1183090

Fonger, N. L., Ellis, A. B., \& Dogan, M. F. (2020). A quadratic growth learning trajectory. Journal of Mathematical Behavior, 59(October 2019), 100795. https://doi.org/10.1016/j.jmathb.2020.100795

Gravemeijer, K. (2004). Local Instruction theories as means of support for teachers in reform mathematics education. Mathematical Thinking and Learning, 6(2), 105-128. https://doi.org/10.1207/s15327833mt10602

Harel, G., \& Koichu, B. (2010). An operational definition of learning. Journal of Mathematical Behavior, 29(3), 115-124. https://doi.org/10.1016/j.jmathb.2010.06.002

Howe, R. (2018). Learning and using our base ten place value number system: theoretical perspectives and twenty-first century uses. ZDM. https://doi.org/10.1007/s11858-0180996-3 
Isoda, M. (2010). Lesson study: problem solving approaches in mathematics education as a Japanese experience. Procedia - Social and Behavioral Sciences, 8, 17-27. https://doi.org/10.1016/j.sbspro.2010.12.003

Land, T. J., Tyminski, A. M., \& Drake, C. (2019). Examining aspects of teachers' posing of problems in response to children's mathematical thinking. Journal of Mathematics Teacher Education, 22(4), 331-353. https://doi.org/10.1007/s10857-018-9418-2

Özkubat, U., Karabulut, A., \& Rüya, E. (2020). Mathematical problem-solving processes of students with special needs: a cognitive strategy instruction model ' solve it!'. International Electronic Journal of Elementary Education, 12(5), 405-416. https://doi.org/10.26822/iejee.2020562131

Prediger, S., Gravemeijer, K., \& Confrey, J. (2015). Design research with a focus on learning processes: an overview on achievements and challenges. ZDM - Mathematics Education, 47(6), 877-891. https://doi.org/10.1007/s11858-015-0722-3

Rakes, C. R., \& Ronau, R. N. (2019). Rethinking mathematics misconceptions : using knowledge structures to explain systematic errors within and across content domains. International Journal of Research in Education and Science, 5(1), 1-21.

Simon, M. A. (2018). An emerging methodology for studying mathematics concept learning and instructional design. Journal of Mathematical Behavior, 52(October 2017), 113121. https://doi.org/10.1016/j.jmathb.2018.03.005

Simon, M. A., Placa, N., \& Avitzur, A. (2016). Participatory and anticipatory stages of mathematical concept learning: Further empirical and theoretical development. Journal for Research in Mathematics Education, 47(1), 63-93. https://doi.org/10.5951/jresematheduc.47.1.0063

Stephan, M., \& Akyuz, D. (2012). A proposed instructional theory for integer addition and subtraction. Journal for Research in Mathematics Education, 43(4), 428-464. https://doi.org/10.5951/jresematheduc.43.4.0428

Sun, X. H. (2018). Bridging whole numbers and fractions: problem variations in Chinese mathematics textbook examples. ZDM. https://doi.org/10.1007/s11858-018-01013-9

Sztajn, P., Confrey, J., Wilson, P. H., \& Edgington, C. (2012). Toward a theory of teaching. Educational Researcher, 41(5), 147-156. https://doi.org/10.3102/0013189X12442801

Verschaffel, L., Schukajlow, S., Star, J., \& Dooren, W. Van. (2020). Word problems in mathematics education : a survey. ZDM. https://doi.org/10.1007/s11858-020-01130-4

Weber, E., \& Lockwood, E. (2014). The duality between ways of thinking and ways of understanding: Implications for learning trajectories in mathematics education. Journal of Mathematical Behavior, 35, 44-57. https://doi.org/10.1016/j.jmathb.2014.05.002

Weber, E., Walkington, C., \& Mcgalliard, W. (2015). Expanding notions of " learning trajectories " in mathematics education. Mathematical Thinking and Learning, 17(4), 253-272. https://doi.org/10.1080/10986065.2015.1083836

Widodo, S. A., Prihatiningsih, A., \& Taufiq, I. (2021). Single subject research: use of interactive video in children with developmental disabilities with dyscalculia to introduce natural numbers. Participatory Educational Research, 8(2), 94-108. https://doi.org/10.17275/per.21.31.8.2

Xin, Y. P. (2018). The effect of a conceptual model-based approach on 'additive' word problem solving of elementary students struggling in mathematics. ZDM. https://doi.org/10.1007/s11858-018-1002-9

Zhang, S., Cao, Y., Wang, L., \& Li, X. (2019). Characteristics of teaching and learning single-digit whole number multiplication in china: the case of the nine-times table. ZDM - Mathematics Education, 51(1), 81-94. https://doi.org/10.1007/s11858-018-01014-8 